\title{
Coarse bedload routing and dispersion through tributary confluences
}

\author{
Kurt S. Imhoff and Andrew C. Wilcox \\ Department of Geosciences, 32 Campus Drive \#1296, University of Montana, Missoula, MT 59812, USA \\ Correspondence to: Kurt S. Imhoff (kurt.imhoff@umontana.edu)
}

Received: 31 October 2015 - Published in Earth Surf. Dynam. Discuss.: 17 December 2015

Revised: 16 June 2016 - Accepted: 5 July 2016 - Published: 26 July 2016

\begin{abstract}
Sediment routing fundamentally influences channel morphology and the propagation of disturbances such as debris flows. The transport and storage of bedload particles across headwater channel confluences, which may be significant nodes of the channel network in terms of sediment routing, morphology, and habitat, are poorly understood, however. We investigated patterns and processes of sediment routing through headwater confluences by comparing them to published results from lower-gradient confluences and by comparing the dispersive behavior of coarse bedload particles between headwater confluence and non-confluence reaches. We addressed these questions with a field tracer experiment using passive-integrated transponder and radio-frequency identification technology in the East Fork Bitterroot River basin, Montana, USA. Within the confluence zone, tracers tended to be deposited towards scour-hole and channel margins, suggesting narrow, efficient transport corridors that mirror those observed in prior studies, many of which are from finer-grained systems. Coarse particles in some confluence reaches experienced reduced depositional probabilities within the confluence relative to upstream and downstream of the confluence. Analysis of particle transport data suggests that variation in the spatial distribution of coarse-sediment particles may be enhanced by passing through confluences, though further study is needed to evaluate confluence effects on dispersive regimes and sediment routing on broader spatial and temporal scales.
\end{abstract}

\section{Introduction}

The transport and storage of mobile sediment particles through channel networks, i.e., sediment routing (Swanson and Fredriksen, 1982), link sediment supply, flow, and channel morphology and thereby regulate channel evolution (Church, 2002, 2006). In headwater regions, where hillslope-channel connectivity is strong, storage and downstream routing of sediment inputs reflect the influence of spatially and temporally variable forcing by hillslope (e.g., debris flows) and fluvial processes (Montgomery and Buffington, 1997; Brooks and Brierley, 1997; Prosser et al., 2001; Lancaster and Casebeer, 2007). Discrete pulses of coarse sediment delivered to streams can travel downstream as a translating bedload wave, by dispersion, or by a combination of translation and dispersion (Lisle et al., 2001; Sklar et al., 2009).
Analyses of dispersion based on the premise that particle motion is a random walk have represented downstream transport as a series of intermittent steps and rests (Einstein, 1937). This approach has informed flume and field studies seeking to identify characteristic probability distributions of step length and rest periods (e.g., Hubbell and Sayre, 1964; Yang and Sayre, 1971; Bradley et al., 2010). Various statistical distributions (e.g., exponential and gamma functions) have been found to approximate spatial distributions of bedload-particle displacements in flume and field conditions (e.g., Hassan et al., 1991; Bradley and Tucker, 2012; Martin et al., 2012; Haschenburger, 2013; Phillips et al., 2013) and have been used to approximate dispersive regimes in gravel-bed channels, including plane-bed (Bradley and Tucker, 2012), pool-riffle (Liébault et al., 2012; Milan, 2013), and braided systems (Kasprak et al., 2014). Long-term tracer experiments have noted evolving spatial 


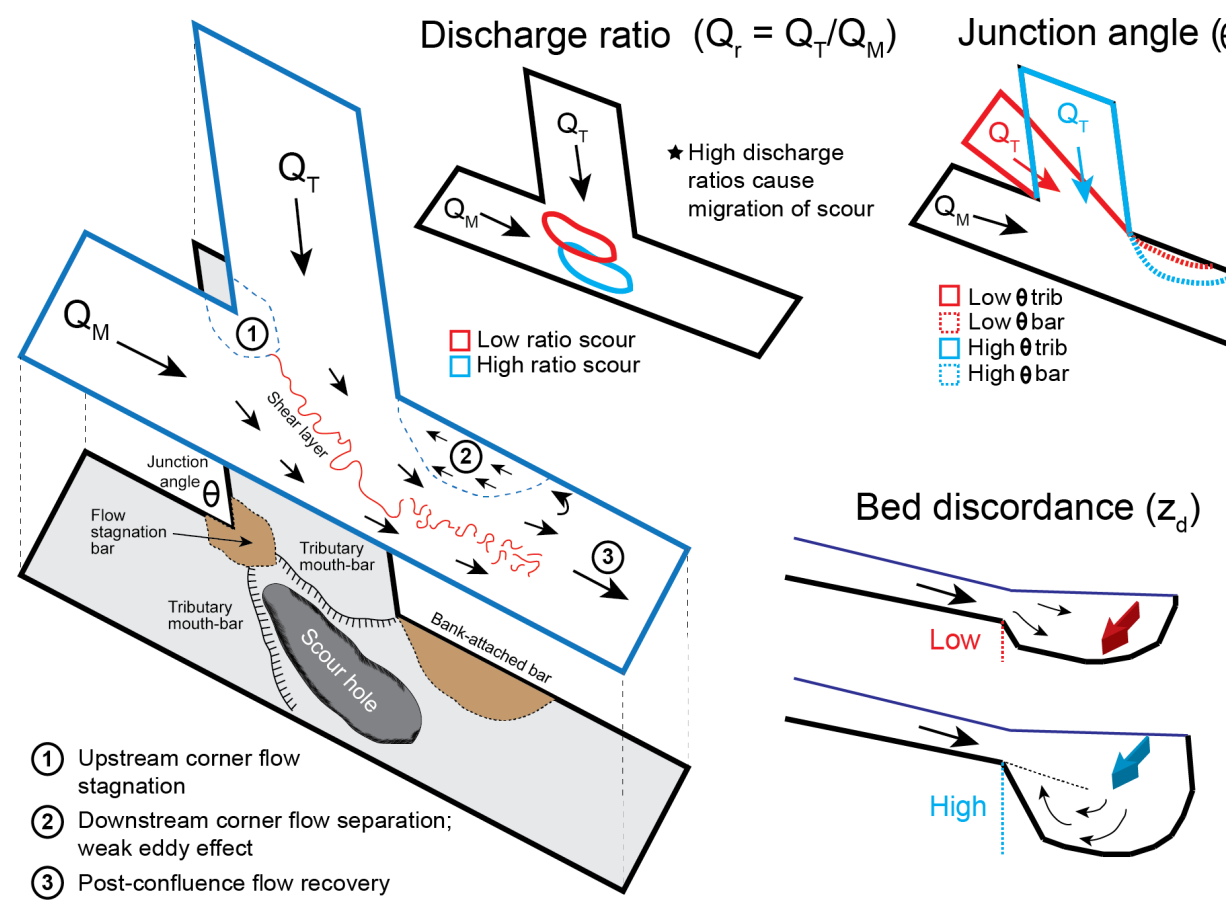

Figure 1. Flow (top left) and morphology (bottom left) in a gravel-bed confluence (after Best, 1987). Key variables influencing hydraulics and morphology include discharge ratio $\left(Q_{\mathrm{r}}\right)$, junction angle $(\theta)$, bed discordance $\left(z_{\mathrm{d}}\right)$, and upstream planform geometry (not pictured).

distributions of bedload particles, suggesting that best-fit statistical distributions may differ depending on the degree of vertical mixing, often a function of time (Haschenburger, 2013). Downward advection of particles into the streambed can reduce the probability of re-entrainment and thus slow streamwise advection (Pelosi et al., 2016). Dispersion models predicting a smooth spatial distribution therefore may not adequately capture the true dispersive behavior of bedload particles across multiple channel morphologies.

The dispersive behavior of coarse-sediment particles has also been considered in terms of changes in the variance of particle displacements with time (e.g., Phillips et al., 2013). Sediment dispersion is thus treated as analogous to one-dimensional diffusion in the downstream direction, with potential diffusion dynamics that include normal diffusion, where the variance of particle displacements increases linearly with time, and anomalous diffusion, which includes both superdiffusion and subdiffusion, when variance increases more quickly or more slowly with time than the linear case, respectively (Metzler and Klafter, 2000; Nikora et al., 2002; Olinde and Johnson, 2015). Improved understanding of variability in dispersive regimes among channel types and other controls on sediment dispersion is needed, however, to facilitate sediment-routing predictions.

Nodes of the channel network that may be especially important with respect to sediment routing are tributary confluences, where point sources of flow and sediment connect tributary to trunk streams (Rice et al., 2008; Rice, 2016). The importance of confluences in sediment routing, as well as their morphologic significance, may depend on factors including drainage densities (i.e., frequency of confluences; Benda et al., 2004a), the magnitude and frequency of disturbances such as debris flows (Benda and Dunne, 1997; Hoffman and Gabet, 2007), and the relative differences in flow, sediment caliber, and load between tributaries and the trunk streams they enter (Fig. 1) (Knighton, 1980; Richards, 1980; Ferguson et al., 2006; Swanson and Meyer, 2014; Rice, 2016). Morphological effects stemming from disturbancederived confluence deposits may extend spatially, well beyond the area of flow convergence, and temporally, persisting for $\sim 10^{2}-10^{4}$ years (Lancaster and Casebeer, 2007). Study of confluences in light of disturbance deposits and morphological heterogeneity has led to the network dynamics hypothesis (NDH; Benda et al., 2004a, b), which considers the spatial arrangement of confluences in river networks and how they affect local and nonlocal channel morphological characteristics. Channel confluences also represent biological "hot spots", forcing spatial heterogeneity in habitat types and in various habitat metrics and influencing longitudinal distributions of aquatic organisms (Rice et al., 2001; Gomi et al., 2002; Clay et al., 2015).

Whereas sediment dynamics and the morphology of headwater confluences can be primarily influenced by disturbances such as debris flows (Benda and Dunne, 1997), what we refer to as "equilibrium" confluence morphology, reflecting feedbacks between flow hydraulics, sediment transport, and morphology, can also develop and persist (Fig. 1). Such confluences are well-studied in sand- and gravel-bed river 


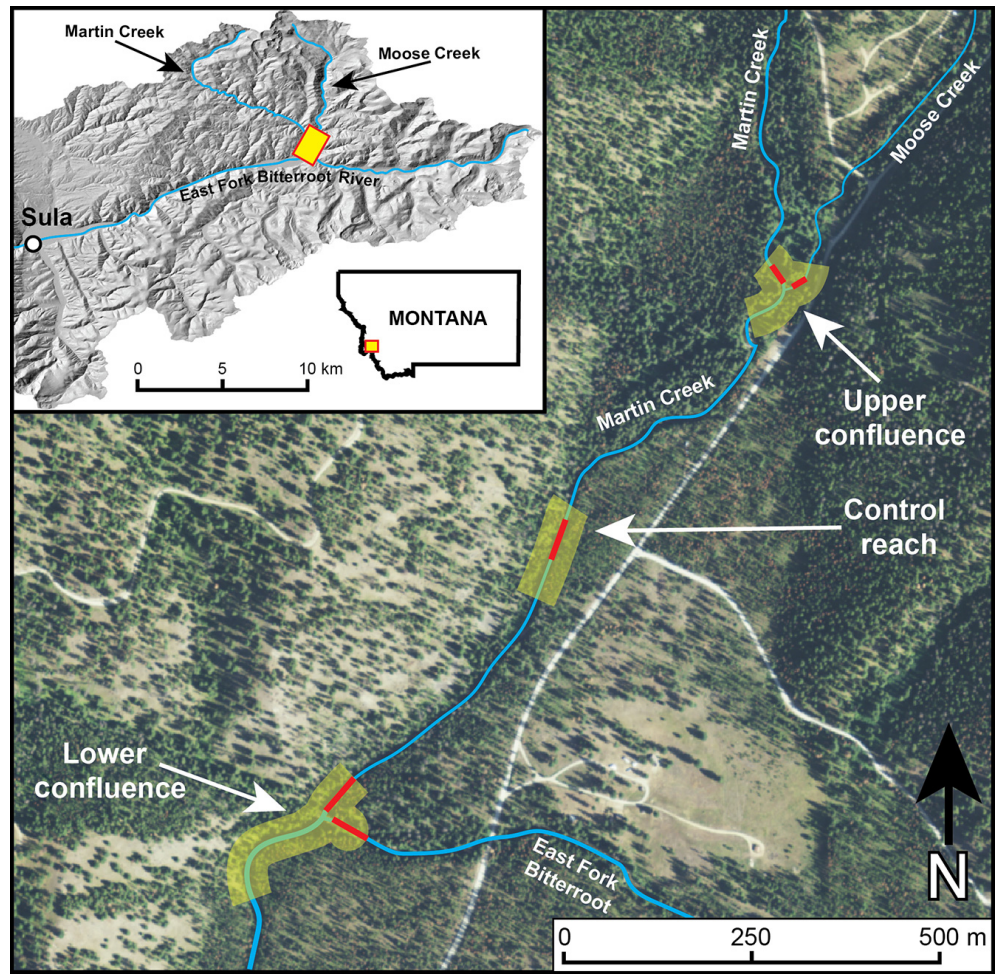

Figure 2. Study area, including location within the East Fork Bitterroot River's headwaters (upper left) and three study sites: upper and lower confluences and a control reach, outlined in yellow; individual reaches in which PIT-tagged particles were seeded are outlined in red.

systems and typically feature a central scour hole, tributarymouth bars, and bank-attached bars in areas of flow recirculation and stagnation (Best, 1987 1988; Rhoads, 1987; Roy and Bergeron, 1990; Biron et al., 1996; Boyer et al., 2006; Rhoads et al., 2009; Ribeiro et al., 2012). Physical controls on confluence hydraulics and associated morphology include junction angle $(\Theta)$, bed discordance $\left(z_{\mathrm{d}}\right)$, discharge ratio $\left(Q_{\mathrm{r}}\right)$ (Fig. 1), and upstream planform curvature (Ashmore and Parker, 1983; Best, 1987; Biron et al., 1996; Rhoads and Sukholodov, 2004; Boyer et al., 2006; Constantinescu et al., 2012; Ribeiro et al., 2012). Sediment transport through equilibrium confluences, however, is poorly understood (Best and Rhoads, 2008), limiting the understanding of how confluences influence local- and network-scale patterns of sediment routing.

In this study we assess how coarse bedload particles are routed through equilibrium confluences in mountain-river headwaters. We address two questions: (i) How do sedimentrouting patterns through equilibrium confluences compare to those described in other, primarily lower-gradient gravel-bed river systems? (ii) How do equilibrium confluences affect the dispersive behavior of coarse bedload particles compared to non-confluence reaches? We address these questions with a tracer experiment conducted through two headwater confluences and a non-confluence control reach. We compare spatial distributions of mobilized particles among study sites and apply a dimensionless impulse framework (Phillips et al., 2013) to observed tracer behavior to explore the effects of confluences on sediment routing. We also evaluate our results and their implications in the context of theory regarding confluences and sediment routing through headwater networks. Our study contributes to the growing body of work on particle dispersion and transport dynamics in mountain rivers and is, to our knowledge, the first to investigate these topics with respect to sediment routing through confluences in a field setting.

\section{Methods}

Here we describe our study area and the preparation, deployment, and measurement of coarse bedload tracer particles. We then describe the analyses we conducted that allow the comparison of particle displacement through the study confluences to that of the control reach and prior transport studies in gravel-bed river systems. This involved the assessment of displacement distributions and a dimensionless impulse, with the goal of evaluating and comparing dispersive regimes. Additional details on these analyses, beyond what is provided below, are in the Supplement and Imhoff (2015). 


\subsection{Study area}

We selected a study area in the East Fork Bitterroot (EFB) River basin in western Montana, USA (Fig. 2) that is typical of semiarid, snowmelt-dominated, montane headwater systems. This location lacks recent physical disturbances (e.g., post-wildfire debris flows) and contains confluences exhibiting characteristics of the equilibrium morphology described above. The field site drains $298 \mathrm{~km}^{2}$ of forested and alpine mountainous terrain, in both the Sapphire Mountains and Pintler Range, ranging in elevation from 1584 to $2895 \mathrm{~m}$. Sediment supplied to channels is comprised of quartzite, argillite, siltite, and feldspathic granitic rock, eroded from metasedimentary Belt Supergroup and Idaho Batholith sources. Annual precipitation is about $0.6 \mathrm{~m} \mathrm{yr}^{-1}$, based on data from the Tepee Point weather station $1.4 \mathrm{~km}$ from the EFB (Western Regional Climate Center Remote Automated Weather Station, 2015). Runoff is dominated by spring snowmelt, with flows capable of mobilizing coarse bedload typically occurring in similar streams between March and July. Human influences from roads and other land uses are minimal in the study area.

Two tributary confluences mark the upstream and downstream extent of the study area. These are herein referred to as the upper confluence, where Moose Creek and Martin Creek combine, and, $1 \mathrm{~km}$ downstream, the lower confluence, where Martin Creek enters the EFB. The tributary and main stem stream of each study confluence are considered as separate reaches for the purpose of separately considering incipient motion and transport behavior of tracers starting in each. Between the study confluences is a plane-bed control reach. Combined discharge in the upper confluence is approximately half that of the lower confluence.

Because the site is ungauged, we installed HOBO-U20 water level loggers to record the stage at $15 \mathrm{~min}$ intervals during the 2014 study period. One transducer was placed along a surveyed cross section of the bed at each study reach. We also periodically manually measured water surface elevations and, during wadeable conditions, stream velocities. Above-average flows during the study period reflected that year's large snowpack. Snow water equivalent at snow telemetry (SNOTEL) sites within $50 \mathrm{~km}$ of the study area registered above $150 \%$ of normal on 1 April 2014 (http: //www.wcc.nrcs.usda.gov/snow/). We estimated the spring 2014 peak flow to have a 3.5- to 4-year recurrence interval, based on transducer data, flood-frequency regression equations developed for western Montana streams (Parrett and Johnson, 2004), and analysis of a downstream US Geological Survey gauge. Flood flows peaked between 25 May and 4 June 2014 (Fig. 3).

To characterize study-reach morphology, we completed topographic surveys and grain-size measurements. Topography was surveyed using a Leica TS06 total station during the initial tracer deployment (March 2014), before spring runoff high flows, and the summer (July-September) recovery cam-

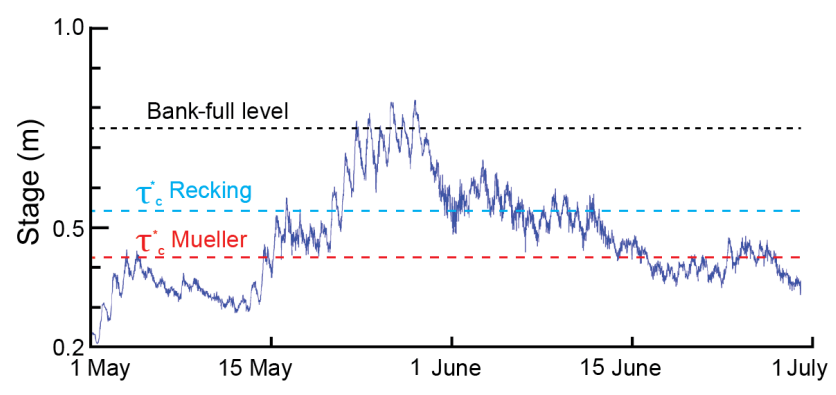

Figure 3. Stage hydrograph during spring 2014 runoff period at lower-confluence (East Fork Bitterroot River) study site. Estimated bank-full level, based on cross section topography surveyed at transducer location, is shown as horizontal dotted line.

paign. Topographic surveys entailed longitudinal profiles, to determine slope, and cross sections at the location of pressure transducers, for use in the incipient motion estimates described below. We also surveyed bedform extents to produce a bedform map. Surface grain-size distributions were measured using Wolman pebble counts across each study reach. Channel slopes, dimensions, grain sizes, and confluence characteristics are shown in Table 1 (also see the Supplement).

\subsection{Bedload tracer preparation, deployment, and measurement}

Our study employed passive-integrated transponder (PIT) and radio-frequency identification (RFID) technology for tagging and tracing bedload particles. PIT tags are highly recoverable, durable, and cost-effective relative to other particle tracing methods (e.g., Lamarre et al., 2005; Bradley and Tucker, 2012; Chapuis et al., 2015). Moreover, PIT-tagging allows for analyses of transport of both bed-material populations and specific subsets of the grain population (e.g., by size, shape, lithology), displacement distributions and their evolution over time, and other aspects of transport dynamics.

We collected gravel and cobble particles from Moose Creek, upstream of our study reaches, in January 2014 for tagging. Using a $1 \mathrm{hp}$ drill press, holes $8 \mathrm{~mm}$ wide by $30 \mathrm{~mm}$ long were drilled using a $\sim 0.8 \mathrm{~mm}$ diamond-tipped drill bit. We tagged cobbles with median axes mostly between 60 and $130 \mathrm{~mm}$ (Fig. 4, Table 2). Many of the tracer particles were larger than the bed $D_{50}$ (Table 1), because particles with $b$ axes below $45 \mathrm{~mm}$ often fractured during drilling. We assumed our tracer particles, which fell within the $D_{37}$ to $D_{70}$ size fraction of bed materials, to be representative of the coarser fraction of mobile bedload particles. The results and interpretation of our sediment tracers thus do not apply for the entire mobile bedload population in this system.

The PIT tags used in this study are 12 and $23 \mathrm{~mm}$ halfduplex, read-only tags from Oregon RFID. Vertical read range varies based on tag orientation, battery level, noise 
Table 1. Channel morphology and bed-material grain-size characteristics at each study reach. Width and depth values are bank-full dimensions, as measured along surveyed cross sections; $Q_{\mathrm{r}}, \theta$, and $z_{\mathrm{d}}$ are illustrated and defined in Fig. 1. Upper- and lower-confluence reaches are denoted by $(U)$ and $(L)$, respectively.

\begin{tabular}{lcccccccc}
\hline Study reach & $S$ & $\begin{array}{c}\text { Width } \\
(\mathrm{m})\end{array}$ & $\begin{array}{c}\text { Depth } \\
(\mathrm{m})\end{array}$ & $\begin{array}{c}D_{50} \\
(\mathrm{~m})\end{array}$ & $\begin{array}{c}D_{84} \\
(\mathrm{~m})\end{array}$ & $Q_{\mathrm{r}}^{\mathrm{a}}(\mathrm{avg})$ & $\Theta$ & $\begin{array}{c}z_{\mathrm{d}} \\
(\mathrm{m})\end{array}$ \\
\hline Moose Creek $(U)$ & 0.018 & 11 & 0.76 & 0.05 & 0.10 & 0.63 & $86^{\circ}$ & 0.16 \\
Martin Creek $(U)$ & 0.029 & 7 & 0.94 & 0.06 & 0.15 & & & - \\
Control reach & 0.016 & 15 & 0.78 & 0.06 & 0.13 & - & - & - \\
Martin Creek $(L)$ & 0.017 & 15 & 0.80 & 0.07 & 0.12 & 0.45 & & 0 \\
East Fk. Bitterroot $(L)$ & 0.016 & 16 & 1.03 & 0.07 & 0.14 & & & \\
\hline
\end{tabular}

a Calculated by dividing the smaller trunk stream by volume over the main stem. $Q_{\mathrm{r}}=Q($ Moose $) / Q($ Martin $)$ in the upper confluence, and $Q$ (Martin) $/ Q$ (East Fork) in the lower confluence.

proximity, and other factors but is generally 0.25 to $0.5 \mathrm{~m}$. Previous work has identified horizontal and vertical detection ranges at $0.5 \mathrm{~m}$ (Lamarre et al., 2005) and $0.25 \mathrm{~m}$ (Bradley and Tucker, 2012). Chapuis et al. (2014) assessed RFID detection ranges and observed higher uncertainty in radial detection distance than reported in other studies. Uncertainty in tracer position is highest for solitary, buried tracers, which are not visible via snorkel survey and have the largest detection radius; clusters of buried tracers, in contrast, have reduced detection ranges via tag interference. We oriented the antenna parallel to the surface of the bed, at a height of about $0.2 \mathrm{~m}$ (after Chapuis et al., 2014). For our analysis, we considered tracer movement below the threshold of detection as immobile and assigned a travel distance of $0 \mathrm{~m}$ (after Phillips and Jerolmack, 2014). Particles moving beyond the threshold of detection were labeled the "mobile" fraction. In total, 428 cobble and gravel tracers were prepared for deposition into the three study reaches (Table 2).

We installed the PIT-tagged tracers before the onset of the spring snowmelt, in late March and early April 2014. Our seeding method involved loosely seeding tracer particles on the bed surface near the channel thalweg in a grid (Fig. 5). Mimicking the arrangement of fluvially deposited gravels and minimizing the influence of the initial condition of particle deployment is a challenge in tracer studies, but a regular grid such as ours provides a reproducible initial condition and is consistent with previous work (Ferguson and Wathen, 1998). A sparse grid like the one employed here minimizes disturbance to the bed and flow field (Bradley and Tucker, 2012) while simultaneously avoiding "confusing" the PIT tag detection equipment, which encounters issues when dealing with clusters of particles (Chapuis et al., 2014). The gridded surface ranged from 7 to $13 \mathrm{~m}$ wide. We deployed PIT-tagged tracers at equal distances upstream from the confluence in each tributary. Initial tracer positions were recorded using the total station.

Field recovery campaigns to detect tracer locations and measure particle displacement took place after recession of high flows, once the streams were wadeable. The bed was scanned with a $0.5 \mathrm{~m}$ diameter loop antenna in conjunction

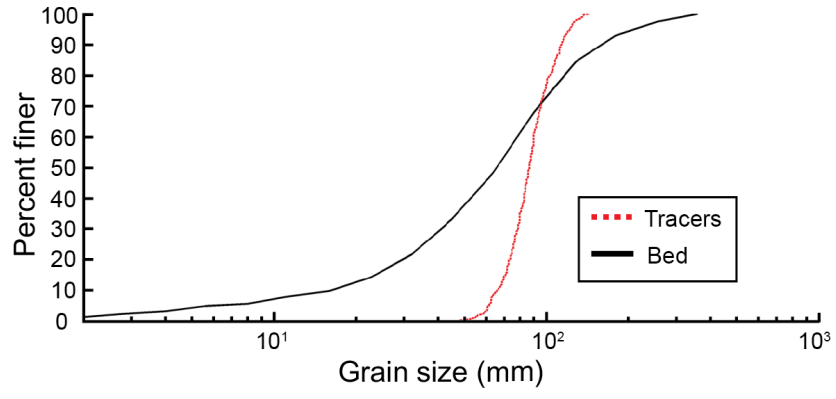

Figure 4. Grain-size distribution of tagged tracers (red) and streambed (black) composite over all study sites.

with a backpack reader. Once a tracer was located, the loop antenna was brought towards its detection field from all directions. This helped to identify other tracers in a cluster by reading different tags first, depending on the direction the cluster is approached. Each tracer's position was recorded using the total station. The uncertainty associated with individual total station measurements of tracer position and travel distance is $\pm 0.20 \mathrm{~m}$ (Bradley and Tucker, 2012). We also employed a snorkel survey to identify if tracers were buried or clustered together. Visible tracers were occasionally surrounded by other tracers in shallow pockets. At all sites, we scanned the area with the loop antenna for $200 \mathrm{~m}$ downstream of the last detected particle to limit omission of any far-traveling tracers, which influence the tail character of displacement distributions. The position of far-traveling tracers was recorded with a Trimble GEOXH 6000 GPS.

\subsection{Analyses of tracer behavior}

To investigate how tracers routed through confluences compared to those in our plane-bed control reach, we compared the spatial distribution of tracers at initial deployment and after the 2014 flood among sites by plotting the distribution of tracers versus streamwise distance. Differences in the pre- and post-flood distributions are indicative of transport distances and of changes in depositional probability; e.g., a 
Table 2. Tracer recovery and transport statistics by study reach.

\begin{tabular}{lccccccc}
\hline Study reach & $n^{\mathrm{a}}$ & $n_{\text {rec }}^{\mathrm{b}}$ & $\begin{array}{c}\text { Recovery } \\
(\%)\end{array}$ & $D_{50}(\mathrm{~m})$ & $(X \pm \sigma)_{\text {tot }}^{\mathrm{d}}(\mathrm{m})^{\mathrm{c}}$ & $\begin{array}{c}(X \pm \sigma)_{\operatorname{mob}}^{\mathrm{d}} \\
(\mathrm{m})\end{array}$ & $\begin{array}{c}X_{\max } \\
(\mathrm{m})\end{array}$ \\
\hline Moose Creek $(U)$ & 65 & 53 & 82 & 0.077 & $7.4 \pm 6.6$ & $8.5 \pm 6.4$ & 24.5 \\
Martin Creek $(U)$ & 62 & 42 & 68 & 0.081 & $3.8 \pm 4.1$ & $4.4 \pm 4.1$ & 20.6 \\
Control reach & 97 & 83 & 86 & 0.080 & $4.2 \pm 5.3$ & $4.9 \pm 5.4$ & 22.7 \\
Martin Creek $(L)$ & 103 & 71 & 68 & 0.082 & $14.6 \pm 22.9$ & $16.4 \pm 24$ & 133 \\
East Fk. Bitterroot $(L)$ & 101 & 74 & 73 & 0.080 & $47.4 \pm 56.3$ & $49.4 \pm 56.6$ & 211 \\
\hline
\end{tabular}

a Number of tracers deployed. ${ }^{b}$ Number of tracers recovered. ${ }^{c} X$ is average transport distance; $\sigma$ is standard deviation. ${ }^{d}$ "Tot" and "mob" describe (1) the total tracer population and (2) tracers moving beyond $0.5 \mathrm{~m}$.

reduction in the slope of the distribution from pre-flood to post-flood conditions indicates reduced depositional probability and enhanced transport (after Haschenburger, 2013). We nondimensionalized transport distances by scaling each tracer's transport distance $\left(X_{i}\right)$ by its $b$ axis diameter $\left(D_{i}\right)$. We then calculated normalized transport distance, $X_{\mathrm{n}}$ (after Phillips et al., 2013):

$X_{\mathrm{n}}=\frac{\frac{X_{i}}{D_{i}}}{<\frac{X}{D}>}$,

where $(\langle X / D\rangle)$ is the mean displacement length for the 2014 flood at each study reach. The variance of dimensionless transport distances was also calculated (after Phillips et al., 2013):

$\sigma^{2}=<\left(\frac{X_{i}}{D_{i}}-<\frac{X}{D}>\right)^{2}>$

where $\sigma^{2}$ is the variance for the 2014 flood for each tracer population.

We also analyzed tracer displacement data with respect to a cumulative dimensionless impulse $I^{*}$, which provides a measure of the time-integrated fluid momentum above the threshold of particle motion (Phillips et al., 2013):

$I^{*}=\int_{t_{i}}^{t_{f}} \frac{\left(U_{\mathrm{e}}^{*}\right) \mathrm{d} t}{D_{50}}$,

where $t_{i}$ and $t_{f}$ are start and end times, respectively, for flow above a critical threshold of motion of bed materials and $U_{\mathrm{e}}^{*}$ is excess shear velocity, which is the difference between the shear velocity $\left(U^{*}=\sqrt{g R S}\right.$, where $g$ is gravitational acceleration, $R$ is hydraulic radius, and $S$ is channel slope) and the critical shear velocity $\left(U_{\mathrm{c}}^{*}\right)$ associated with the initial motion of bed particles. Flume studies have identified that a mobilized sediment particle shows a total displacement that is proportional to $U_{\mathrm{e}}^{*}$ (Lajeunesse et al., 2010; Martin et al., 2012). In addition, analysis of channels across climatic settings and channel types found that morphology is adjusted in a manner whereby $U_{\mathrm{c}}^{*}$ is typically slightly exceeded during floods, allowing bed-material transport while maintaining channel stability (Phillips and Jerolmack, 2016). We used $I^{*}$ to compare
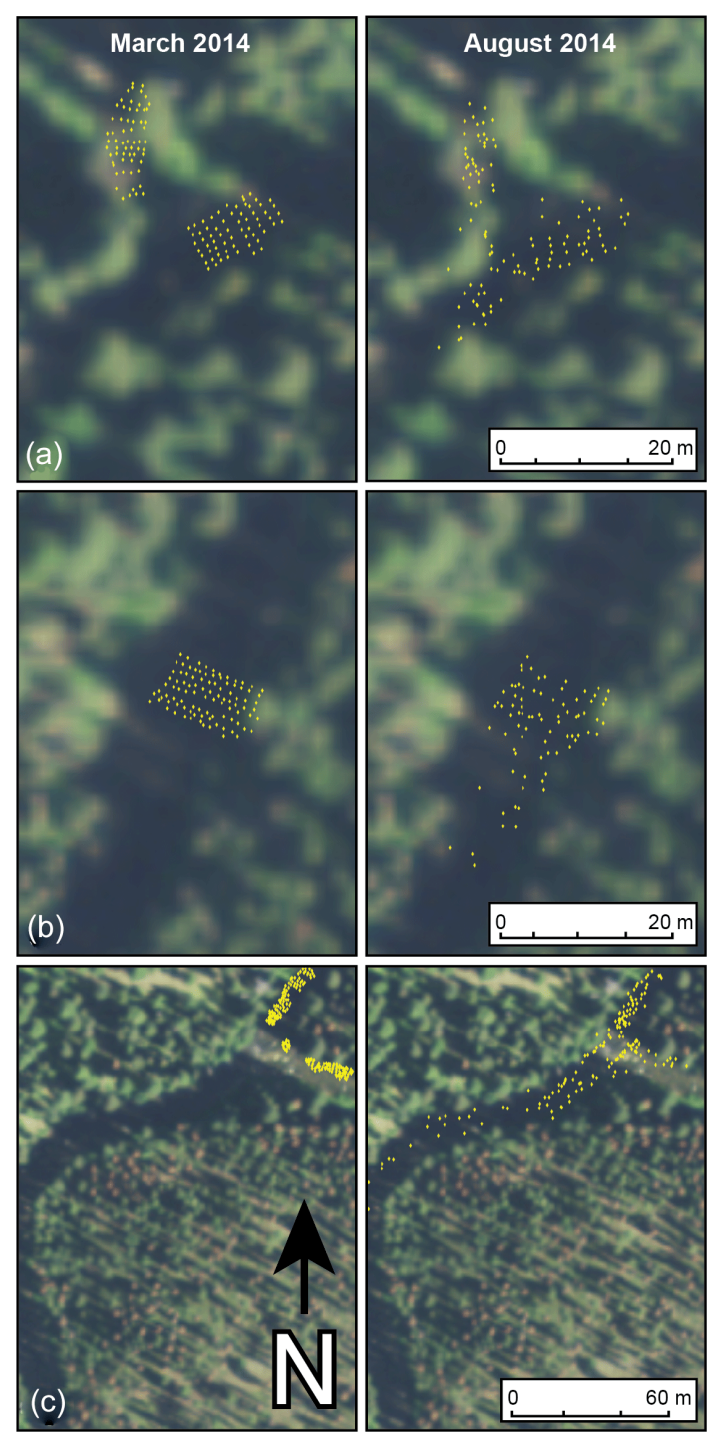

Figure 5. Tracer positions at initial installation (left) and following the 2014 flood (right) at (a) the upper confluence, (b) the control reach, and (c) the lower-confluence reaches.

tracer transport distances against the cumulative $U_{\mathrm{e}}^{*}$ imparted 
on grains. We determined $I^{*}$ for each of our five seed reaches and, as a means of comparing confluence and non-confluence reaches, evaluated the extent to which each data set deviated from a linear relationship between $\langle X / D\rangle$ and $I^{*}$, which can be considered indicative of a difference in dispersive regimes (Phillips et al., 2013).

Because our tracer equipment could not directly detect initial motion conditions, we estimated $U_{\mathrm{c}}^{*}$ by back-calculating $R_{\mathrm{c}}$ (critical hydraulic radius associated with the mobilization of the average-sized tracer particle) from the critical Shields number $\left(\tau_{\mathrm{c}}^{*}\right)$, a nondimensional shear stress associated with the incipient motion of particles in a flow:

$\tau_{\mathrm{c}}^{*}=\frac{\rho g R_{\mathrm{c}} S}{\left(\rho_{\mathrm{s}}-\rho_{\mathrm{w}}\right) g D_{50}}$,

where $\rho_{\mathrm{s}}$ is sediment bulk density (assumed to equal $\left.2650 \mathrm{~kg} \mathrm{~m}^{-3}\right)$ and $\rho_{\mathrm{w}}$ is water density $\left(1000 \mathrm{~kg} \mathrm{~m}^{-3}\right)$. We determined $\tau_{\mathrm{c}}^{*}$ using two different empirical approaches, which we selected based on their derivation in gravel-bed systems similar to our study sites and our ability to measure required inputs. For the first estimate, we used the reference dimensionless shear stress relation for steep gravel- and cobble-bed rivers of Mueller et al. (2005):

$$
\tau_{\mathrm{c}, \text { Mueller }}^{*} \approx \tau_{\mathrm{r}}^{*}=2.18 S+0.021
$$

where $\tau_{\mathrm{r}}^{*}$ is a reference shear stress, which we assume is similar to $\tau_{\mathrm{c}}^{*}$ (after Mueller et al., 2005). The relation of Mueller et al. (2005) is derived from field, rather than laboratory, data, including a study site, Halfmoon Creek, Colorado, that is similar to the EFB in terms of slope, grain size, width, planebed morphology, and snowmelt hydrology. For a second estimate of $\tau_{\mathrm{c}}^{*}$, we used the mobility shear stress $\left(\tau_{\mathrm{m}}^{*}\right)$ equation of Recking (2013), which was empirically developed using bedload transport data from gravel-bed transport studies in mountain streams:

$\tau_{\mathrm{c}, \text { Recking }}^{*} \approx \tau_{\mathrm{m}}^{*}=(5 S+0.06)\left(\frac{D_{84}}{D_{50}}\right)^{4.4 \sqrt{S}-1.5}$.

Analogously to Eq. (5), we assume that $\tau_{\mathrm{m}}^{*}$ approximates $\tau_{\mathrm{c}}^{*}$ (after Recking, 2013).

These two estimates for $\tau_{\mathrm{c}}^{*}$ were paired with stage data to estimate the cumulative duration of flow above the threshold of motion, which is difficult to measure directly (Charru et al., 2004). At each seed reach, we used pressure transducer data to identify the critical flow depth $\left(h_{\mathrm{c}}\right)$ that corresponds with the $R_{\mathrm{c}}$ for initiating sediment motion, thus linking stage data to estimates of channel-averaged $U^{*}$ during the 2014 flood hydrograph. Estimates of $U_{\mathrm{e}}^{*}$ were then integrated across the 2014 hydrograph to estimate $I^{*}$. Because Eq. (3) is restricted to flow above the threshold of sediment motion, $I^{*}$ limits the frequency-magnitude distribution of $U^{*}$ to conditions relevant to estimated sediment transport and only considers the momentum excess imparted by the flow on sediment particles. This approach adopts the simplifying assumption of a constant $U_{\mathrm{c}}^{*}$ for a given field site (after Phillips et al., 2013; Phillips and Jerolmack, 2016), although we recognize that $U_{\mathrm{c}}^{*}$ varies in both space and time (e.g., Turowski et al., 2011).

\section{Results}

\subsection{Field observations of tracer displacement}

We recovered $68-86 \%$ of the seeded tracers, depending on the reach (Table 2). Recovery was greatest within study reaches with low $D_{84}$ values and short transport distances, including the control reach and Moose Creek (Table 2). Recent tracer studies using RFID technology have found comparable recovery rates: $25-78 \%$ (Liébault et al., 2012), 93-98\% (Bradley and Tucker, 2012), 62-100\% (Phillips et al., 2013), and $40 \%$ (Chapuis et al., 2015).

Similar percentages of recovered tracers (41, 39, and $50 \%$ ) left each seed reach. At the upper confluence, tracer configurations within the seed reach retained the signature of their streamwise spatial pattern in Moose Creek after movement but not in Martin Creek, which contained more boulders to facilitate trapping and clustering of particle tracers (Fig. 5). Particles seeded in Moose Creek also constituted the majority of tracers exported into the confluence itself. Within the confluence particles tended to be deposited towards channel margins and were less frequently deposited within the scour hole (Fig. 6). Particles deposited within the scour hole were segregated by the contributing stream. Tracers from the upper-confluence seed reaches had short travel distances and, even after being mobilized, remained within the confluence zone (Fig. 6).

Particles recovered in the lower confluence largely retained the signature of the gridded arrangement of their initial positioning at both seed reaches, even after mobilization. The relative contribution of tracers into the confluence was more evenly distributed than in the upper confluence: $55 \%$ of deposited tracers came from the East Fork, with the remaining $45 \%$ from Martin Creek. Similar to the upper confluence, tracer particles remained segregated as they progressed through the confluence, stranding preferentially on bank-attached depositional bars. Deposition within the scour hole was limited and segregated, further agreeing with the upper confluence. An additional group of tracers, seeded at the upstream junction corner, was immobile. Similar to the upper confluence, large boulders were effective in trapping mobile tracer particles. Of the recovered tracers in the entire lower confluence, $23 \%$ left the confluence zone completely, with $58 \%$ of post-confluence tracers originating in the East Fork and $42 \%$ in Martin Creek. Recovered particles downstream of the lower confluence ceased to be segregated after about $30 \mathrm{~m}$ and were recovered approximately in the channel center. 
(a)

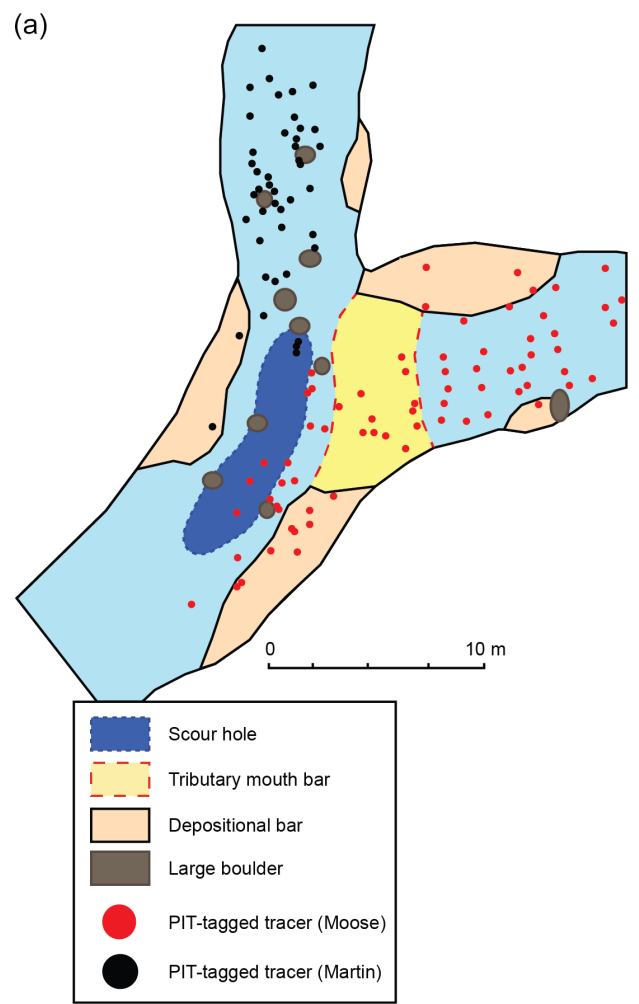

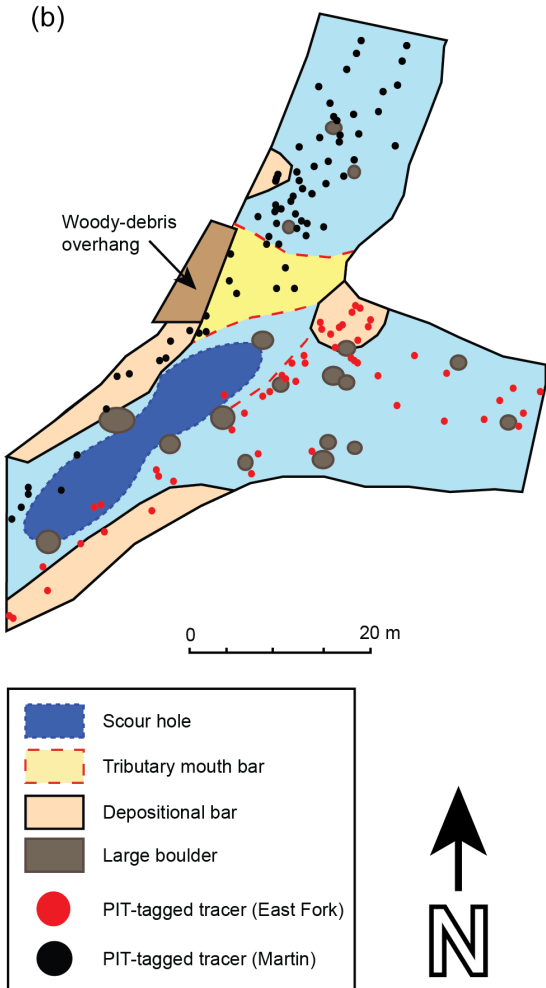

Figure 6. Digitized patch map of bedforms and tracer recovery positions at the (a) upper and (b) lower confluences.

Table 3. Critical shear velocity $\left(U_{\mathrm{c}}^{*}\right)$ and dimensionless impulse $\left(I^{*}\right)$ at each study reach.

\begin{tabular}{lccr|crr}
\hline & \multicolumn{3}{c|}{$\tau_{\mathrm{c}, \text { Mueller }}^{*}$} & \multicolumn{3}{c}{$\tau_{\mathrm{c}, \text { Recking }}^{*}$} \\
Study reach & $\tau_{\mathrm{c}}^{*}$ & $U_{\mathrm{c}}^{*}\left(\mathrm{~m} \mathrm{~s}^{-1}\right)$ & $I^{*}$ & $\tau_{\mathrm{c}}^{*}$ & $U_{\mathrm{c}}^{*}\left(\mathrm{~m} \mathrm{~s}^{-1}\right)$ & $I^{*}$ \\
\hline Moose Creek $(U)$ & 0.06 & 0.23 & 602000 & 0.08 & 0.27 & 14900 \\
Martin Creek $(U)$ & 0.08 & 0.29 & 310000 & 0.11 & 0.34 & 37600 \\
Control reach & 0.06 & 0.23 & 425000 & 0.07 & 0.25 & 88400 \\
Martin Creek $(L)$ & 0.06 & 0.25 & 1200000 & 0.09 & 0.31 & 86000 \\
East Fk. Bitterroot $(L)$ & 0.06 & 0.25 & 1900000 & 0.07 & 0.29 & 577000 \\
\hline
\end{tabular}

\subsection{Particle displacement distributions}

Tracers from the upper confluence, upon entering the confluence, exhibited reduced depositional probabilities and enhanced particle transport (Fig. 7a).This is demonstrated by changes in the shape of the overall distribution of tracers that correlates to entering the confluence. Slope reduction upon entering the confluence zone indicates a reduced depositional probability within the confluence (Haschenburger, 2013), whereas similar slopes among the pre- and post-flood distributions would indicate a consistent depositional probability in space. Although most of the particles seeded in Martin Creek did not enter the upper confluence, those that did experienced a similar reduction in depositional probability as the Moose Creek tracers. The stepped pre-flood distributions of upper-confluence particles (Fig. 7a) reflected prevailing ice conditions and likely translated into the post-flood distributions. Regardless, additional particles lie within the zone of reduced depositional probability post-flood, indicating enhanced transport within the confluence.

In the control reach, observed transport distances were comparable to those in the upper-confluence reaches (Fig. 7a, b). This was in spite of considerably larger Reckingestimate impulse values, reflecting the fact that the upperconfluence reaches together provide the control reach's component discharge (Table 3). Within the post-flood spatial position of tracers in the control reach, small steps were present (e.g., at about the 40th percentile), which appear to correspond to steps present in the pre-flood distribution (e.g., near the 60th percentile), reflecting downstream translation of the curve across a portion of its distribution (Fig. 7b). The postflood distribution decays exponentially, suggesting a rela- 

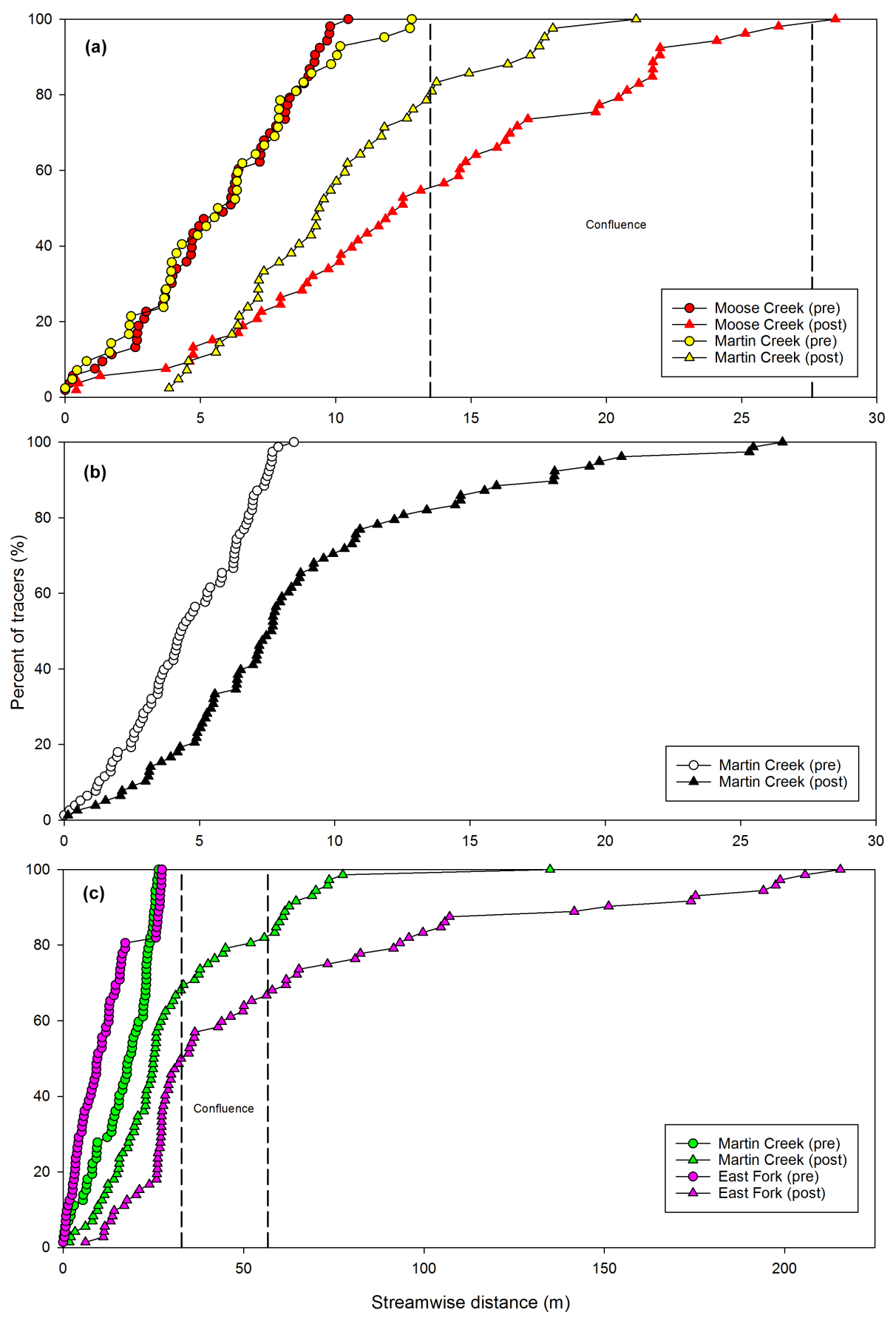

Figure 7. Spatial distribution of tracer positions at the time of initial deployment (pre) and after the 2014 flood (post) for (a) the upper confluence, (b) the control reach, and (c) the lower confluence. The confluence zones are bracketed with dotted vertical lines. Note the altered $x$ axis scale in $(\mathbf{c})$.

tively constant depositional probability throughout the reach (Fig. 7b), in contrast to the depositional probabilities at the upper confluence.

At the lower confluence, transport distances are greater than in the upstream reaches (Fig. 7c). Evidence of enhanced transport within the confluence is strong for Martin Creek: depositional rates upstream and downstream of the conflu- ence exceed those within the confluence, and there is no relic pattern carried over from the pre-flood spatial distribution of tracers (Fig. 7c). Confluence effects are less clear among the East Fork tracers, largely because tracers seeded at the upstream junction corner in the East Fork did not enter the confluence and are visible as a near-vertical line in the pre- ( $>80$ th percentile) and post- (20-40th percentile) flood 


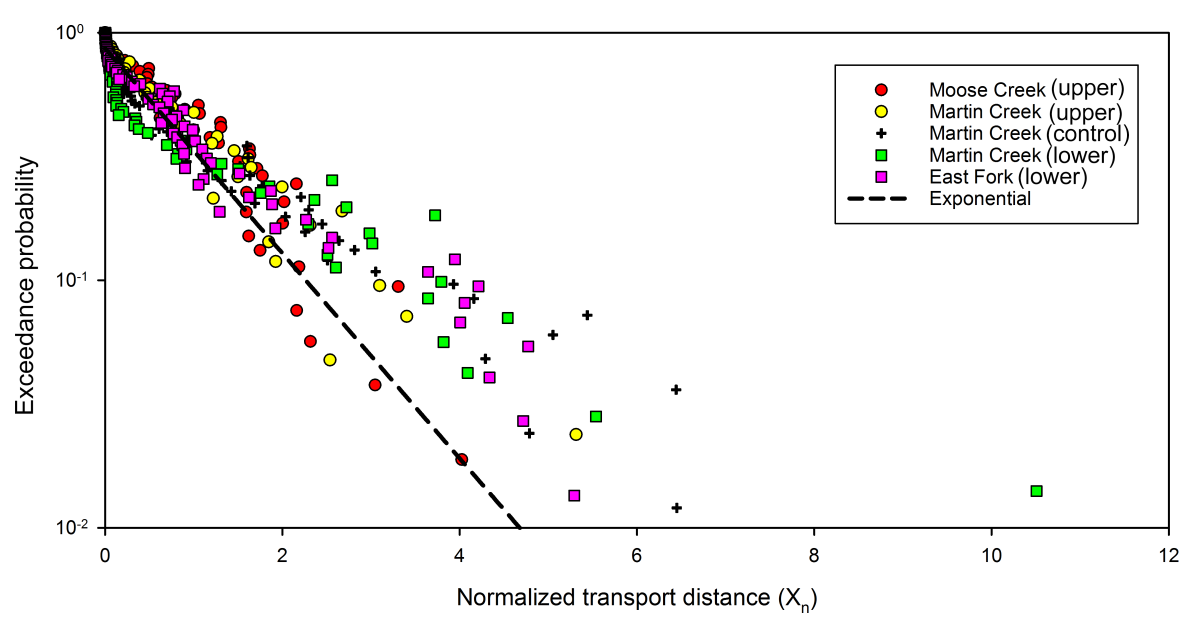

Figure 8. Normalized transport distances $\left(\mathrm{X}_{n} ;\right.$ Eq. 1) in all five study reaches, with exponential fit plotted for comparison.

spatial distributions (Fig. 7c). Other than these tracers the East Fork tracers show a similar pattern as in Martin Creek. Overall, the dispersive growth of the lower-confluence tracers assumes a thin-tailed decay similar to that of the control, though the altered depositional probability within the confluence, especially among Martin Creek tracers, differentiates the control and lower-confluence distributions.

Dimensionless displacement distributions for both confluence and non-confluence reaches are reasonably characterized by an exponential distribution (Fig. 8). This further suggests that particle dispersion at the site is thin-tailed during the 2014 flood. Front-running particles at the upperconfluence reaches travel relatively shorter distances beyond the population average compared to the lower confluence. This, along with far shorter transport distances, suggests that larger cumulative excess shear stresses (i.e., larger $I^{*}$ values) correlate to increased transport and greater dispersive growth, as asserted by Phillips et al. (2013). The control reach plots similarly to the lower confluence in Fig. 8, despite tracer transport metrics comparable to the upper confluence (Table 2; Fig. 7) - far fewer particles exceed the average transport distance for the population than at the upper confluence.

\subsection{Dimensionless impulse}

Our estimates of the critical Shields number ranged from 0.06 to 0.11 (Table 3), slightly larger than often assumed values of $\tau_{\mathrm{c}}^{*}$ (e.g., $\tau_{\mathrm{c}}^{*}=0.045$; Church, 2006). For all

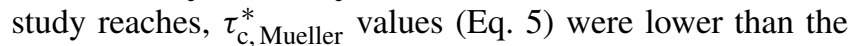
$\tau_{\mathrm{c}, \text { Recking }}^{*}$ values (Eq. 6), resulting in correspondingly lower $U_{\text {c }}^{*}$ values. These calculations indicate that flow exceeded the threshold of motion for 8-37 ( $\left.\tau_{\mathrm{c}, \text { Mueller }}^{*}\right)$ or 1-17 ( $\left.\tau_{\mathrm{c}, \text { Recking }}^{*}\right)$ days, with the lower confluence experiencing the longest duration above the critical level. The distribution of $U^{*}$ and $I^{*}$ scale with channel dimensions and peak discharge, with the upper-confluence seed reaches experiencing smaller $U^{*}$ and $I^{*}$ values than the control reach and lower confluence (Table 3). Moose Creek, for example, is wider and shallower than Martin Creek at the upper confluence and requires a larger discharge increase to move from the Mueller to Recking incipient-motion threshold estimate. This results in reach-specific variation in sensitivity to the estimation method for incipient motion. We found that $I^{*}$ scaled well with tracer displacement (Table 3), substantiating its applicability for assessing coarse-particle transport at the EFB.

We found $\langle X / D\rangle$ to conform to a linear relation to $I^{*}$ (Fig. 9a), and the variance $\left(\sigma^{2}\right)$ of dimensionless transport distances showed a power-law relationship to $I^{*}$ (Fig. 9b). These relationships are consistent with the predictions and findings of Phillips et al. (2013) and Phillips and Jerolmack (2014) regarding the broad applicability of normalized travel distances and the impulse for characterizing bedload transport. The linear fit between $\langle X / D\rangle$ and $I^{*}$ supports the notion that $I^{*}$ may be used to correlate flow strength with travel distance across multiple sites. Between confluence reaches, greater impulse values correlated to larger average and maximum transport distances as well as dispersive growth (Table 3). A linear fit through the origin provided a similar quality of fit to that found by Phillips et al. (2013). Fits could be improved by only considering the relationship between confluence reaches: the control reach has similar displacement but higher $I^{*}$ values than reaches at the upper confluence, giving it the highest residual from the best-fit curve in both cases. Normalization of $I^{*}$ by frictional resistance did not significantly improve the collapse of our tracer data.

\section{Discussion}

\subsection{Coarse-sediment routing through confluences}

Our study used PIT/RFID technology to investigate coarsesediment transport across tributary confluences of moun- 

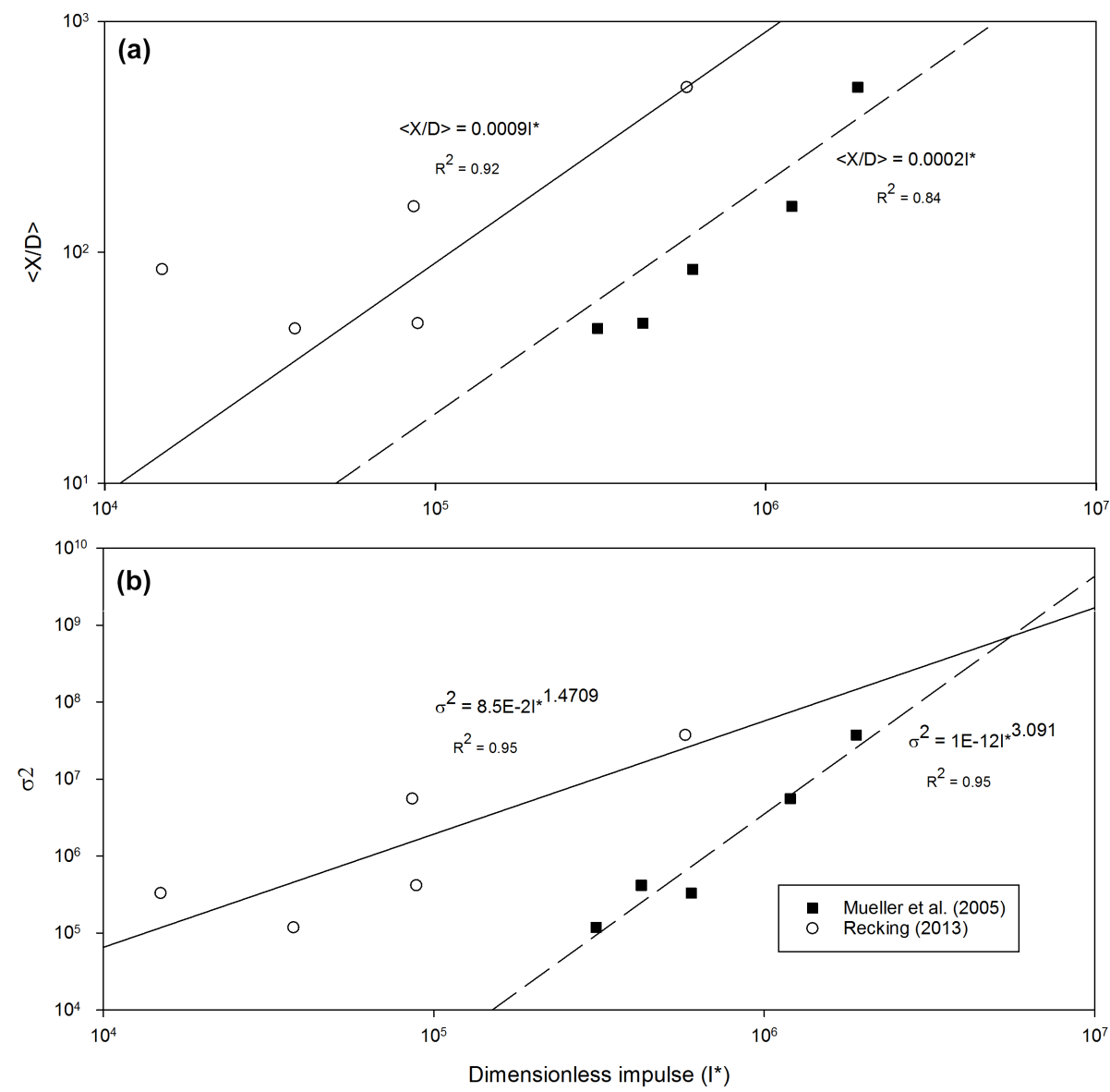

Figure 9. Linear and power-law relations between dimensionless impulse and (a) mean displacement length $(<X / D>)$ and $(\mathbf{b})$ variance $\left(\sigma^{2}\right.$; Eq. 2) for each tracer population.

tain streams. Maximum transport distances along scourhole flanks and segregation are similar to the findings of Mosley (1976) and Best (1988). Because we detect no tracers beyond the extent of the upper confluence, we take the depositional pattern in Fig. 6 to reflect a tendency of our tracers to route along, rather than through, the scour hole. We see similar depositional patterns for tracers that were detected within the lower confluence and posit that similar transport corridors apply. We consider these transport patterns to reflect the controlling influences of $\Theta$ and $Q_{\mathrm{r}}$; the simple upstream planform geometry and minimal bed discordance $\left(z_{\mathrm{d}}\right)$ at our sites suggest that those factors exert little influence on morphodynamics in our study confluences. Observed discordance between scour and tributary-mouth bars at our study confluences ( 0.6 and $1.4 \mathrm{~m}$, respectively) exceeds that of Roy and Bergeron (1990; $\sim 0 \mathrm{~m}$ at $\Theta=15$ ), supporting observations that scour is largely absent at low $\Theta$ values (Benda and Cundy, 1990).

Our data also agree with the assertions of Best (1988) and others as to how the position and orientation of the scour hole is influenced by $Q_{\mathrm{r}}$. Increased penetration of flow from the tributary at the upper confluence, due to higher
$Q_{\mathrm{r}}$, forced the scour hole towards the middle of the confluence, as opposed to the lower confluence where the scour was shifted by greater discharge from the East Fork Bitterroot. Observed feedbacks between confluence morphology and particle transport suggest similar confluence morphodynamics as observed in past studies (e.g., Mosley, 1976; Best, 1987; Boyer et al., 2006; Rhoads et al., 2009), though in a higher-gradient setting with more headwaters than previous work.

\subsection{Effects of confluences on dispersion}

Our comparison of the pre- and post-flood spatial distributions of bedload tracers provides evidence of reduced depositional probability and enhanced transport within confluences (Fig. 7). This is most evident in Moose Creek, at the upper confluence, and Martin Creek, at the lower confluence. Where the pre-flood spatial distribution of particles is not continuous, such as the upper Martin Creek reach and the East Fork, these patterns are less evident. The spatial distribution of tracers in the control reach does not substantially differ from the lower-confluence reaches, even when the con- 
fluence zone is clearly transport-efficient. This may be because the confluence zone in the lower-confluence reaches represents a small portion of the total tracer transport distances, which are greater here than in upstream reaches, muting confluence effects on transport when the entire distribution of tracers is considered and as tracer transport becomes more influenced by plane-bed morphology than confluence effects. At the upper confluence, in contrast, the confluence zone occupied a much larger portion of the transport reach, and consequently the post-flood distribution differs more from the control.

Exceedance probabilities of normalized transport distances show a steeper form in the upper-confluence reaches than the control reach and lower confluences (Fig. 8). The steeper trend ensures that front-running tracers travel a relatively shorter distance beyond the population average, though a greater proportion of the tracer population travels near or beyond the average distance. The control reach, despite similar average and maximum tracer transport distances to the upper-confluence reaches, shows more similar distributions to the lower-confluence reaches. This difference is suggestive of enhanced transport within the equilibrium confluence; when tracers entering the confluence are able to continue transporting downstream, a greater proportion of tracers will reside in the front of the plume, past the average transport distance, as we see with the upper confluence. Because the trend is absent for the lower confluence, we postulate that the confluence effect (enhanced transport, reduced deposition) is muted once particles have transported a sufficient distance beyond the confluence zone. Despite evidence suggesting confluence effects on transport, our study lacks sufficient spatial and temporal resolution to differentiate in a statistically rigorous manner between confluence and nonconfluence reaches - all study reaches may be considered as exhibiting a thin-tailed dispersive growth pattern, given their linear form in semi-log space. Recent works suggest that thin-tailed dispersion is dominant for coarse bedload particles (e.g., Hassan et al., 2013), and our work is no exception.

\subsection{Confluences and large-scale sediment routing}

To develop a more complete understanding of how dispersive patterns observed on the scale of individual confluences influence sediment connectivity and routing on the larger basin scale in mountain watersheds, longer-term studies across a larger number of confluence sites and channel morphologies are needed. Such work could test how confluence effects on sediment routing are dependent on both confluence (e.g., $Q_{\mathrm{r}}$, $\Theta$ ) and basin (e.g., shape, drainage density, and network geometry) characteristics (Benda et al., 2004a; Rice, 2016). Such studies could also further test the network dynamics hypothesis (NDH) of Benda et al. (2004b), which considers that the likelihood of morphologically significant perturbations to main stem channels, in the form of aggradational sediment deposits, increases in the vicinity of confluences due to upstream disturbance and may be cumulatively more significant in compact basins (also see Rice, 2016). Additional field measurement of sediment transport across confluences would complement the recent application of remote, automated methods of predicting tributary-driven aggradation at confluences and testing of the effect of basin shape on confluence aggradation (Rice et al., 2016).

Network structure, in terms of both geometry and variations in sediment transport capacity, has been found to influence how sediment inputs in headwaters propagate downstream through basins (e.g., Czuba and Foufoula-Georgiou, 2014; Gran and Czuba, 2016) and relates to the questions raised in the NDH about basin shape and associated confluence effects (Benda et al., 2004a, b). In our study area and in semiarid mountain watersheds in general, for example, postfire erosion is an important sediment source with implications for humans and aquatic ecosystems; downstream propagation of post-fire sediment inputs may vary depending on basin shape and confluence effects. For example, propagation of sediment routing may differ between unglaciated, compact basins with dendritic channel networks (as are present in our study area and the surrounding Sapphire Mountains) compared to formerly glaciated, elongate basins with trellis drainage networks (as are present in the Bitterroot Range $\sim 30 \mathrm{~km}$ to the west of our study sites) (Benda et al., 2004a). Discontinuity in coarse-sediment transfer can emerge when competence is reduced and particles enter long-term storage (e.g., Tooth et al., 2002; Fryirs, 2013; Bracken et al., 2015), including where the morphology of landforms surrounding confluences creates sediment buffers between tributaries and trunk streams (Fryirs and Gore, 2014) or as a result of downward advection into the streambed (Pelosi et al., 2016). These points highlight the importance of understanding the dispersive behavior of coarse bedload particles, including in various basin shapes and in locations both lacking recent disturbance, with equilibrium confluence morphology, and in disturbance-driven, aggradational confluences (Benda et al., 2004b).

\section{Conclusions}

In gravel-bed headwater systems, equilibrium confluences are unique locations that may affect local patterns of sediment transport and deposition. Our study is the first to date of tracer-based coarse-sediment routing through mountain-river confluences. We observed that, on the reach scale, coarse sediment is routed through confluences along the flanks of a well-defined scour hole, in agreement with observations and flume studies from other gravel-bed systems. Certain confluence reaches showed evidence for enhanced transport during a single snowmelt flood, although understanding whether confluences influence bedload dispersion in a geomorphically significant manner on larger spatial and temporal scales would require further study. The dimensionless impulse metric (Phillips et al., 2013) was shown to correlate to 
tracer transport and dispersion over a single flood event, further supporting its use in future sediment transport studies. Our study also illustrates the utility of tracer studies using PIT/RFID technology for providing field-based insights into sediment transport dynamics. Longer-term sediment transport studies across confluence and non-confluence reaches, combined with an analysis of changes in bed elevation and texture in intervening reaches to place the work in a mass conservation framework, would further clarify sedimentrouting patterns in mountain channel networks and thus inform a range of problems. These include the understanding of how confluences influence sediment cascades and connectivity (Fryirs, 2013); links among confluences, sediment routing, and basin morphology (Benda et al., 2004a, b; Rice, 2016); and applied problems including solid-phase contaminant transport (Bradley et al., 2010), cosmogenic radionuclide accumulation (Gayer et al., 2008), sediment budgeting (Malmon et al., 2005), and the duration and topographic impact of pulses on aquatic habitat (Lisle et al., 2001).

\section{Data availability}

Pre- and post-flood tracer data are provided by the authors in a publically accessible online data repository (Imhoff and Wilcox, 2015) at http://doi.pangaea.de/10.1594/PANGAEA. 855346 .

\section{The Supplement related to this article is available online at doi:10.5194/esurf-4-591-2016-supplement.}

Acknowledgements. We thank P. A. Duvillard, A. Maphis, D. Davis, M. Jahnke, and A. Sawyer for field assistance; M. Hassan, L. Eby, M. Maneta, S. Bywater-Reyes, and R. Manners for insight into the planning and implementation of this work; N. Bradley and C. Legleiter for aid in model use and coordinate transformation; and C. Phillips for assistance in performing impulse analyses. Comments from two anonymous reviewers and from Associate Editor Dimitri Lague greatly improved the manuscript. This work was supported by the Montana Institute on Ecosystems' award from the National Science Foundation EPSCoR Track-1 program under Grant no. EPS-1101342 and by the Montana Geological Society, the Geological Society of America, and the Northwest Scientific Association.

Edited by: D. Lague

Reviewed by: two anonymous referees

\section{References}

Ashmore, P. and Parker, G.: Confluence scour in coarse braided streams, Water Resour. Res., 19, 392-402, 1983.
Benda, L. and Cundy, W.: Predicting deposition of debris flows in mountain channels, Can. Geotech. J., 27, 409-417, 1990.

Benda, L. and Dunne, T.: Stochastic forcing of sediment routing and storage in channel networks, Water Resour. Res., 33, 2865-2880, 1997.

Benda, L., Andras, K., Miller, D., and Bigelow, P.: Confluence effects in rivers: Interactions of basin scale, network geometry, and disturbance regimes, Water Resour. Res., 40, W05402, doi:10.1029/2003WR002583, 2004a.

Benda, L., Poff, N.L., Miller, D., Dunne, T., Reeves, G., Pess, G., and Pollock, M.: The network dynamics hypothesis: how channel networks structure riverine habitats, BioScience, 54, 413-427, 2004b.

Best, J.: Flow dynamics at river channel confluences: implications for sediment transport and bed morphology, Soc. Econ. Pa., 39, 27-35, 1987.

Best, J.: Sediment transport and bed morphology at river channel confluences, Sedimentology, 35, 481-498, 1988.

Best, J. L. and Rhoads, B. L.: Sediment transport, bed morphology and the sedimentology of river channel confluences, in: River Confluences, Tributaries and the Fluvial Network, edited by: Rice, S. P, Roy, A. G., and Rhoads, B. L., John Wiley \& Sons, Chichester, UK, 2008.

Biron, P., Best, J. L., and Roy, A. G.: Effects of bed discordance on flow dynamics at open channel confluences, J. Hydraul. Eng., 122, 676-682, 1996.

Boyer, C., Roy, A. G., and Best, J.: Dynamics of a river channel confluence with discordant beds: Flow turbulence, bed load sediment transport, and bed morphology, J. Geophys. Res., 111, F04007, doi:10.1029/2005JF000458, 2006.

Bracken, L. J., Turnbull, L., Wainwright, J., and Bogaart, P.: Sediment connectivity: a framework for understanding sediment transfer at multiple scales, Earth Surf. Proc. Land., 40, 177-188, doi:10.1002/esp.3635, 2015.

Bradley, N. and Tucker, G. E.: Measuring gravel transport and dispersion in a mountain river using passive radio tracers, Earth Surf. Proc. Land., 37, 1034-1045, doi:10.1002/esp.3223, 2012.

Bradley, D. N., Tucker, G. E., and Benson, D. A.: Fractional dispersion in a sand bed river, J. Geophys. Res., 115, F00A09, doi:10.1029/2009JF001268, 2010.

Brooks, A. and Brierley, G.: Geomorphic responses of lower Bega River to catchment disturbance, 1851-1926, Geomorphology, 18, 291-304, 1997.

Chapuis, M., Bright, C. J., Hufnagel, J., and MacVicar, B.: Detection ranges and uncertainty of passive Radio Frequency Identification (RFID) transponders for sediment tracking in gravel rivers and coastal environments, Earth Surf. Proc. Land., 39, 2109 2120, doi:10.1002/esp.3620, 2014.

Chapuis, M., Dufour, S., Provansal, M., Couvert, B., and de Linares, M.: Coupling channel evolution monitoring and RFID tracking in a large, wandering, gravel-bed river: Insights into sediment routing on geomorphic continuity through a riffle-pool sequence, Geomorphology, 231, 258-269, doi:10.1016/j.geomorph.2014.12.013, 2015.

Charru, F., Mouilleron, H., and Eiff, O.: Erosion and deposition of particles on a bed sheared by a viscous flow, J. Fluid Mech., 519, 55-80, doi:10.1017/S0022112004001028, 2004. 
Church, M.: Geomorphic thresholds in riverine landscapes, Freshwater Biol., 47, 541-557, doi:10.1046/j.13652427.2002.00919.x, 2002.

Church, M.: Bed material transport and the morphology of alluvial river channels, Annu. Rev. Earth Pl. Sc., 34, 325-354, doi:10.1146/annurev.earth.33.092203.122721, 2006.

Clay, P., Muehlbauer, J., and Doyle, M.: Effect of tributary and braided confluences on aquatic macroinvertebrate communities and geomorphology in an alpine river watershed, Freshwater Science, 34, 845-856, 2015.

Constantinescu, G., Miyawaki, S., Rhoads, B. L., and Sukhodolov, A.: Numerical analysis of the effect of momentum ratio on the dynamics and sediment-entrainment capacity of coherent flow structures at a stream confluence, J. Geophys. Res., 117, F04028, doi:10.1029/2012JF002452, 2012.

Czuba, J. A. and Foufoula-Georgiou, E.: A network-based framework for identifying potential synchronizations and amplifications of sediment delivery in river basins, Water Resour. Res., 50, 3826-3851, doi:10.1002/2013WR014227, 2014.

Einstein, H. A.: Bed load transport as a probability problem, $\mathrm{PhD}$, ETH Zurich, Zurich, Switzerland, 1937.

Ferguson, R. and Wathen, S.: Tracer-pebble movement along a concave river profile?: Virtual velocity in relation to grain size and shear stress transport and deposition, Water Resour. Res., 34, 2031-2038, 1998.

Ferguson, R., Cudden, J. R., Hoey, T. B., and Rice, S. P.: River system discontinuities due to lateral inputs: generic styles and controls, Earth Surf. Proc. Land., 31, 1149-1166, doi:10.1002/esp.1309, 2006.

Fryirs, K.: (Dis)Connectivity in catchment sediment cascades: a fresh look at the sediment delivery problem, Earth Surf. Proc. Land., 38, 30-46, doi:10.1002/esp.3242, 2013.

Fryirs, K. and Gore, D. B.: Geochemical insights to the formation of "sedimentary buffers": Considering the role of tributarytrunk stream interactions on catchment-scale sediment flux and drainage network dynamics, Geomorphology, 219, 1-9, 2014.

Gayer, E., Mukhopadhyay, S., and Meade, B. J.: Spatial variability of erosion rates inferred from the frequency distribution of cosmogenic $3 \mathrm{He}$ in olivines from Hawaiian river sediments, Earth Planet. Sc. Lett., 266, 303-315, doi:10.1016/j.epsl.2007.11.019, 2008.

Gomi, T., Sidle, R. C., and Richardson, J. S.: Understanding processes and downstream linkages of headwater systems, BioScience, 52, 905-916, doi:10.1641/00063568(2002)052[0905:UPADLO]2.0.CO;2, 2002.

Gran, K. B. and Czuba, J. A.: Sediment pulse evolution and the role of network structure, Geomorphology, doi:10.1016/j.geomorph.2015.12.015, in press, 2016.

Haschenburger, J. K.: Tracing river gravels: Insights into dispersion from a long-term field experiment, Geomorphology, 200, 121131, doi:10.1016/j.geomorph.2013.03.033, 2013.

Hassan, M. A., Church, M., and Schick, A. P.: Distance of movement of coarse particles in gravel bed streams, Water Resour. Res., 27, 503-511, 1991.

Hassan, M. A., Voepel, H., Schumer, R., Parker, G., and Fraccarollo, L.: Displacement characteristics of coarse fluvial bed sediment, J. Geophys. Res.-Earth, 118, 155-165, doi:10.1029/2012JF002374, 2013.
Hoffman, D. F. and Gabet, E. J.: Effects of sediment pulses on channel morphology in a gravel-bed river, Geol. Soc. Am. Bull., 119, 116-125, doi:10.1130/B25982.1, 2007.

Hubbell, D. and Sayre, W.: Sand transport studies with radioactive tracers, J. Hydraul. Div., 90, 39-68, 1964.

Imhoff, K. S.: Sediment routing through channel confluences: Particle tracing in a gravel-bed river headwaters, M.S. thesis, University of Montana, Missoula, MT, USA, 2015.

Imhoff, K. S. and Wilcox, A. C.: East Fork Bitterroot RFID tracer data, available at: http://doi.pangaea.de/10.1594/PANGAEA. 855346, last access: 12 December 2015.

Kasprak, A., Wheaton, J. M., Ashmore, P. E., Hensleigh, J. W., and Peirce, S.: The relationship between particle travel distance and channel morphology?: Results from physical models of braided rivers, J. Geophys. Res. Earth, 120, 55-74, doi:10.1002/2014JF003310, 2014.

Knighton, A. D.: Longitudinal changes in size and sorting of stream-bed material in four English rivers, Geol. Soc. Am. Bull., 91, 55-62, 1980.

Lajeunesse, E., Malverti, L., and Charru, F.: Bed load transport in turbulent flow at the grain scale: Experiments and modeling, J. Geophys. Res., 115, F04001, doi:10.1029/2009JF001628, 2010.

Lamarre, H., MacVicar, B., and Roy, A. G.: Using passive integrated transponder (PIT) tags to investigate sediment transport in gravel-bed rivers, J. Sediment. Res., 75, 736-741, doi:10.2110/jsr.2005.059, 2005.

Lancaster, S. T. and Casebeer, N. E.: Sediment storage and evacuation in headwater valleys at the transition between debris-flow and fluvial processes, Geology, 35, 1027-1030, doi:10.1130/G239365A.1, 2007.

Liébault, F., Bellot, H., Chapuis, M., Klotz, S., and Deschâtres, M.: Bedload tracing in a high-sediment-load mountain stream, Earth Surf. Proc. Land, 37, 385-399, doi:10.1002/esp.2245, 2012.

Lisle, T. E., Cui, Y., Parker, G., Pizzuto, J. E., and Dodd, A. M.: The dominance of dispersion in the evolution of bed material waves in gravel-bed rivers, Earth Surf. Proc. Land., 26, 14091420, doi:10.1002/esp.300, 2001.

Malmon, D. V., Reneau, S. L., Dunne, T., Katzman, D., and Drakos, P. G.: Influence of sediment storage on downstream delivery of contaminated sediment, Water Resour. Res., 41, 1-17, doi:10.1029/2004WR003288, 2005.

Martin, R. L., Jerolmack, D. J., and Schumer, R.: The physical basis for anomalous diffusion in bed load transport, J. Geophys. Res., 117, F01018, doi:10.1029/2011JF002075, 2012.

Metzler, R. and Klafter, J.: The random walk's guide to anomalous diffusion: a fractional dynamics approach, Phys. Rep., 339, 1-77, doi:10.1016/S0370-1573(00)00070-3, 2000.

Milan, D. J.: Sediment routing hypothesis for pool-riffle maintenance, Earth Surf. Proc. Land., 38, 1623-1641, doi:10.1002/esp.3395, 2013.

Montgomery, D. R. and Buffington, J. M.: Channel-reach morphology in mountain drainage basins, Geol. Soc. Am. Bull., 109, 596-611, 1997.

Mosley, M. P.: An experimental study of channel confluences, J. Geol., 84, 535-562, 1976.

Mueller, E. R., Pitlick, J., and Nelson, J. M.: Variation in the reference Shields stress for bed load transport in gravelbed streams and rivers, Water Resour. Res., 41, F02016, doi:10.1029/2004WR003692, 2005. 
Nikora, V., Habersack, H., Huber, T., and McEwan, I.: On bed particle diffusion in gravel bed flows under weak bed load transport, Water Resour. Res., 38, 17-1-17-9, doi:10.1029/2001WR000513, 2002.

Olinde, L. and Johnson, J. P. L.: Using RFID and accelerometerembedded tracers to measure probabilities of bed load transport, step lengths, and rest times in a mountain stream, Water Resour. Res., 51, 7572-7589, doi:10.1002/2014WR016120, 2015.

Parrett, C. and Johnson, D. R.: Methods for estimating flood frequency in Montana based on data through water year 1998, USGS Water-Resources Investigations Rep. 03-4308, Reston, VA, USA, 2004.

Pelosi, A., Schumer, R., Parker, G., and Ferguson, R. I.: The cause of advective slowdown of tracer pebbles in rivers: Implementation of Exner-Based Master Equation for coevolving streamwise and vertical dispersion, J. Geophys. Res., 121, 623-637, doi:10.1002/2015JF003497, 2016.

Phillips, C. B. and Jerolmack, D. J.: Dynamics and mechanics of bed-load tracer particles, Earth Surf. Dyn., 2, 513-530, doi:10.5194/esurf-2-513-2014, 2014.

Phillips, C. B. and Jerolmack, D. J.: Self-organization of river channels as a critical filter on climate signals, Science, 352, 694-697, doi:10.1126/science.aad3348, 2016.

Phillips, C. B., Martin, R. L., and Jerolmack, D. J.: Impulse framework for unsteady flows reveals superdiffusive bed load transport, Geophys. Res. Lett., 40, 1328-1333, doi:10.1002/grl.50323, 2013.

Prosser, I. P., Rutherfurd, I. D., Olley, J. M., Young, W. J., Wallbrink, P. J., and Moran, C. J.: Large-scale patterns of erosion and sediment transport in river networks, with examples from Australia, Mar. Freshwater Res., 52, 81-99, doi:10.1071/MF00033_CO, 2001.

Recking, A.: Simple method for calculating reach-averaged bed-load transport, J. Hydraul. Eng., 139, 70-75, doi:10.1061/(ASCE)HY.1943-7900.0000653, 2013.

Rhoads, B. L.: Changes in stream channel characteristics at tributary junctions, Phys. Geogr., 8, 346-361, 1987.

Rhoads, B. L. and Sukhodolov, A. N.: Spatial and temporal structure of shear layer turbulence at a stream confluence, Water Resour. Res., 40, W06304, doi:10.1029/2003WR002811, 2004.

Rhoads, B. L., Riley, J. D., and Mayer, D. R.: Response of bed morphology and bed material texture to hydrological conditions at an asymmetrical stream confluence, Geomorphology, 109, 161173, doi:10.1016/j.geomorph.2009.02.029, 2009.
Ribeiro, M. L., Blanckaert, K., Roy, A. G., and Schleiss, A. J.: Flow and sediment dynamics in channel confluences, J. Geophys. Res., 117, F01035, doi:10.1029/2011JF002171, 2012.

Rice, S. P.: Tributary connectivity, confluence aggradation and network biodiversity, Geomorphology, doi:10.1016/j.geomorph.2016.03.027, in press, 2016.

Rice, S. P., Greenwood, M. T., and Joyce, C. B.: Tributaries, sediment sources, and the longitudinal organisation of macroinvertebrate fauna along river systems, Can. J. Fish. Aquat. Sci., 58, 824-840, doi:10.1139/cjfas-58-4-824, 2001.

Rice, S. P., Roy, A. G., and Rhoads, B. L.: River Confluences, Tributaries and the Fluvial Network, John Wiley \& Sons, Chichester, UK, 2008.

Richards, K. S.: A note on changes in channel geometry at tributary junctions, Water Resour. Res., 16, 241-244, doi:10.1029/WR016i001p00241, 1980.

Roy, A. G. and Bergeron, N.: Flow and particle paths at a natural river confluence with coarse bed material, Geomorphology, 3, 99-112, doi:10.1016/0169-555X(90)90039-S, 1990.

Sklar, L. S., Fadde, J., Venditti, J. G., Nelson, P., Wydzga, M. A., Cui, Y., and Dietrich, W. E.: Translation and dispersion of sediment pulses in flume experiments simulating gravel augmentation below dams, Water Resour. Res., 45, W08439, doi:10.1029/2008WR007346, 2009.

Swanson, F. J. and Fredriksen, R. L.: Sediment routing and budgets?: Implications for judging impacts of forestry practices, in: Sediment Budgets and Routing in Forested Drainage Basins, edited by: Swanson, F. J., Janda, R. J., Dunne, T., and Swanston, D. N., U.S. Forest Service General Technical Report PNW-141, Portland, OR, USA, 129-137, 1982.

Swanson, B. J. and Meyer, G.: Tributary confluences and discontinuities in channel form and sediment texture: Rio Chama, NM, Earth Surf. Proc. Landf., 39, 1927-1943, doi:10.1002/esp.3586, 2014.

Tooth, S., McCarthy, T. S., Brandt, D., Hancox, P. J., and Morris, R.: Geological controls on the formation of alluvial meanders and floodplain wetlands: the example of the Klip River, eastern Free State, South Africa, Earth Surf. Proc. Land., 27, 797-815, doi:10.1002/esp.353, 2002.

Turowski, J. M., Badoux, A., and Rickenmann, D.: Start and end of bedload transport in gravel-bed streams, Geophys. Res. Lett., 38, L04401, doi:10.1029/2010GL046558, 2011.

Yang, C. and Sayre, W.: Stochastic model for sand dispersion, J. Hydraul. Div., 97, 265-288, 1971. 